\title{
Non Medical Interventions for Childhood Diarrhoea Control:Way Forward in Nepal Khanal V, ${ }^{1}$ Bhandari ${ }^{2}{ }^{2}$ Karkee $\mathrm{R}^{3}$
}

\author{
${ }^{1}$ School of Public Health, Curtin University \\ Australia \\ ${ }^{2}$ Health Research and Social Development Forum \\ (HERD), Nepal \\ ${ }^{3}$ Maharajgunj Medical Campus \\ Institute of Medicine, Kathmandu
}

\author{
Corresponding Author \\ Ramjee Bhandari \\ Maharajgunj Medical Campus \\ Institute of Medicine, Kathmandul \\ Email: bhandariramjee@gmail.com
}

Citation

Khanal V, Bhandari R, Karkee R. Non Medical Interventions for Childhood Diarrhoea control: Way Forward in Nepal. Kathmandu Univ Med J 2013;43(3):256-261.

\section{ABSTRACT}

\section{Background}

Diarrhoeal diseases remain a major cause of mortality of children aged under-five years in the developing countries including Nepal. The transmission of diarrhoea mostly caused by biological agents and is facilitated by the behavioural, social and environmental factors. More recently, the concept of prevention altering these factors is getting momentum.

\section{Objective}

To recommend the most effective non medical intervention that can prevent and control childhood diarrhoeal disease in Nepal.

\section{Methods}

Litrature review was conducted to analyse the successful interventions in developing countries. Peer review articles were accessed from "Science direct", "Google Scholar", and "Pubmed". Interventions focussing on social and environmental determinants of diarrhoea were included.

\section{Results}

Four interventions (with primary focus in social and environmental determinants of diarrhoeal disease) were purposively selected, summarized and discussed.

Saniya programme (Burkina Faso 1995 to 1998) is considered successful in modifying the risk behaviours. Intensive hand washing programme (Pakistan 2002 to 2003), a cluster randomized controlled trail, was not sustainable as the results did not last long once the free supply of soap was stopped. School Led Total Sanitation (Nepal 2006) is a participatory, community centred program whose focus is on local ownership. This program approach is effective and feasible for scaling up in Nepal. Global Public Private Partnership for Hand washing with Soap (Ghana 2002) was based on the marketing researches and hence yielded effective results.

\section{Conclusion}

Combination of School Led Total Sanitation and Global Public Private Partnership for hand washing with soap suits Nepal. These interventions focus on creating demand, changing behaviour and thereby, improving the sanitation status.

\section{KEYWORDS}

Burning mouth syndrome, idiopathic, stomatodynia, xerostomia

\section{INTRODUCTION}

Childhood diarrhoeal disease is still a major killer of underfive year's children in developing world. Vulnerability in children increases because of their dependence on others for feeding and hygiene needs. Nepal Demographic and Health Survey (2006) reported that $14 \%$ of under five children had diarrhoea in Nepal. ${ }^{1}$ Diarrhoeal incidence trend in Nepal suggests a remarkable increment from 378 per 1000 children to 598 , but with a sharp decline in the severity and fatality. ${ }^{2}$ It is reported that some 13,000 under five year children still die of diarrhoea in Nepal. ${ }^{34}$ Given that Nepal is striving for reducing childhood mortality by two thirds from the level of 1990s, diarrhoea possesses a great hurdle to achieve the Millennium Development Goal for child survival. ${ }^{2}$ 
Diarrhoea is mainly caused by biological agents and transmitted through faeco-oral route. ${ }^{5}$ Various social and environmental factors such as contaminated food/fluid, improper personal hygiene, waste disposal and feeding practices facilitate the transmission. ${ }^{6-9}$ It is found that $44 \%$ of total diarrhoeal cases were attributed to improper/lack of hand washing; $88 \%$ to open defecation; and $30-60 \%$ to environmental sanitation. ${ }^{10}$ Since the majority of Nepalese (73\%) lack access to basic sanitation, improving sanitation condition is likely to have a great impact in reducing diarrhoeal diseases in Nepal. ${ }^{11}$

A community based diarrhoea control program was launched in 1982 in Nepal.1,12 Control of Diarrhoeal Disease (CDD), a priority program of Ministry of Health and Population, includes strategies such as oral rehydration therapy, breast feeding, proper nutrition (including vitamin A supplementation) and zinc supplementation for ten days along with health promotion efforts. ${ }^{4,12}$ The focus of Nepalese health system has still been on the medical interventions. Although studies suggested a remarkable redution in childhood diarrhoeal through social and environmental intervention, evaluation of such interventions has not been done in Nepal. ${ }^{6-9}$ The momentum of handwashing, open defeacation free declaration, and toilet construction has been going throughout the country, yet there is a need to look at the modality of such successful environmental and social measures. ${ }^{13,14}$ None of the previously published studies suggested a suitable model of intervention in Nepalese context. Therefore,the purpose of this review is to discuss various social and environmental interventions successful in reducing childhood diarrheal disease in developing countries and recommend the appropriate interventions for preventing and controlling diarrhoea among under five years children in Nepal.

\section{METHOD}

Literature review was carried out to identify successful interventions to reduce childhood diarrhoeal disease through socio-environmental interventions. Electronic peer reviewed journals were accessed from "Science direct", "Google scholar" and "Pubmed". To broaden the horizon of the review, other "grey literature' (reports and official documents) were accessed on the respective website of Ministry of Health and Population (MoHP), Nepal, the World Health Organization (WHO) andUnited Nations Children Fund (UNICEF)."Childhood diarrhoea*, Childhood diarrhea*, "Diarrhoea prevention", "Diarrhoea Intervention" "Diarrhoea prevention" were used as key words for literature search.

A total of four studies were summarised and discussed in review. These studies were selected purposively to include the studies which primarily focused on the social and behavioural interventions and with no clinical intervention on it. The studies which focused on (i) interventions focussed on the social and/or environmental determinants of diarrhoea (ii) developing countries and (iii) having some evidence of success in reducing childhood diarrhoea, (iv) published in english language (v) published between 1990 and 2011 were included in this study. We excluded the studies which focussed on the medical interventions such as immunization, nutrition supplements or vitamin $\mathrm{A}$ supplements.

\section{Findings}

We obtained four successful studies which were implemented and have been found successful in reducing childhood diearrhoeal diseases. The findings of four studies selected have been discussed individually whereas summary has been summarized in table 1 .

\section{Intervention 1: Program Saniya, Burkina Faso}

Saniya means cleanliness in local language of Burkina Faso, Africa. ${ }^{15,16}$ The program was started in the urban area of Burkino Faso in 1995, and evaluation was done after completion of the project in 1998. This program was based on basic research foundations and field testing of various methods, messages and techniques. Saniya Program targeted four behavioural components; defecation of children in potty, disposal of child's excreta in toilet, hand washing by mothers after cleaning child's bottom and hand washing of mothers after using toilet. ${ }^{15,16}$ The program utilized five strategies in reaching target groups for behaviour change; (i) utilization of monthly house to house visit, (ii) participatory discussion by health workers, (iii) mobilizing teachers based on curriculum on hygienic practices, (iv)theatre group play performance every week and $(v)$ radio message broadcasting.

Mothers, maids and elder sisters of child, as care taker, were target groups of the program. ${ }^{16}$ In the program area Bubo Dioulasso of the city of Burkina Faso, toilet coverage was high (91\%) as toilet construction was mandatory by law while building houses; and public water supply was good. ${ }^{16}$

By end of program (baseline 1995 and end line 1998), success was mixed. Defecation of child in potty increased from $74 \%$ to $82 \%$ (target $85 \%$ ), child's stool disposed in the toilet increased from $80 \%$ to $84 \%$ (target $90 \%$ ), mother washing their hands after cleaning child's bottom increased from $13 \%$ to $31 \%$ (target 30\%) and mother washing their hands after using toilet increased from $1 \%$ to $17 \%$ (target $15 \%$ ). ${ }^{15-17}$ Though exact outcome in terms of childhood diarrhoeal diseases is not measured, increase in hand washing behaviour and proper disposal of child's excreta are likely to contribute in reducing the incidence of diarrhoea. ${ }^{18,19}$ In conclusion, this project was successful in modifying the risk behaviours of diarrhoeal diseases.

Use of formative research technique, multiple message strategies, locally acceptable behaviour and linking excreta disposable to aesthetic and social values were some of the successful strategies of this project. ${ }^{15,16}$ But on the other side, the project was implemented for a short period ( 3 years), and the duration was not sufficient to see if the 
Table 1. Summary of the Reviewed Interventions.

\begin{tabular}{|c|c|c|c|c|c|}
\hline SN & Name of the Project & Place of Intervention & Risk factor & Strategies & Summary \\
\hline 1 & Program Saniya & Burkina Faso & $\begin{array}{l}\text { Personal Hygiene, } \\
\text { hand washing }\end{array}$ & $\begin{array}{l}\text { utilization of monthly house to } \\
\text { house visit, participatory discus- } \\
\text { sion by health workers, mobilizing } \\
\text { teachers based on curriculum on } \\
\text { hygienic practices, theatre group } \\
\text { play performance every week, and } \\
\text { radio message broadcasting }\end{array}$ & $\begin{array}{l}\text { increase in hand washing } \\
\text { behaviour, increase in proper } \\
\text { disposal of excreta of a child }\end{array}$ \\
\hline 2 & $\begin{array}{l}\text { Intensive Hand washing } \\
\text { Promotion on Childhood } \\
\text { Diarrhoea in High Risk } \\
\text { Community in Pakistan }\end{array}$ & Pakistan & $\begin{array}{l}\text { Hand washing with } \\
\text { soap }\end{array}$ & $\begin{array}{l}\text { hand washing behaviour promo- } \\
\text { tion, printed material distribution, } \\
\text { and slide shows }\end{array}$ & $\begin{array}{l}\text { incidence of diarrhoea re- } \\
\text { duced by } 53 \%\end{array}$ \\
\hline 3 & $\begin{array}{l}\text { School Led Total Sanita- } \\
\text { tion, Nepal }\end{array}$ & Nepal & $\begin{array}{l}\text { Multiple approach, } \\
\text { Sanitation, hand } \\
\text { washing }\end{array}$ & $\begin{array}{l}\text { school children as change agents, } \\
\text { local resources utilisation and risk } \\
\text { behaviour focus (toilet use, hand } \\
\text { washing promotion) }\end{array}$ & $\begin{array}{l}250 \text { school catchment areas } \\
\text { are declared as open defeca- } \\
\text { tion free areas, } \\
\text { Impact on diarrhoeal disease } \\
\text { has not been measured, } \\
\text { toilet construction and use } \\
\text { increased, open defecation } \\
\text { free areas increased }\end{array}$ \\
\hline
\end{tabular}
$4 \quad$ Global Public Private Partnership for Hand washing with Soap, Ghana

$\begin{array}{lll}\begin{array}{l}\text { Ghana (Implemented } \\ \text { in multi country) }\end{array} & \begin{array}{l}\text { Hand washing with } \\ \text { Soap }\end{array} & \begin{array}{l}\text { mass media campaign, district and } \\ \text { community level activities and } \\ \text { direct consumer contact }\end{array}\end{array}$

hand washing before eating reached $41 \%$ from $2 \%$, after toilet increased from $4 \%$ to $13 \%$ and after cleaning child's bottom increased from $2 \%$ to $41 \%$. changed behaviours were for long term. ${ }^{16}$ The program components except for health workers involvement with community were non-participatory. ${ }^{15,16}$

Intervention 2: Intensive Hand washing Promotion on

A cluster randomized controlled study was implemented in 36 low income neighbourhood of Pakistani communities in April 2002 to April 2003. ${ }^{20}$ The study area was a low sanitation area having high childhood mortality from diarrhoeal disease, high level of water contamination from human feaces, and with no prior targeted interventions for hand washing. The study included two tier interventions; the first was hand washing promotion and the second was supply of soaps for hand washing. Total of 300 households were supplied with plain soap, and 300 households with antibacterial soap as intervnetion, and 300 households were included as control group. The two intervention groups were reached with health promotion messages through video show, pamphlets and slideshow to demonstrate the adverse effects resulting from contaminated hands.

At the end of the program, there were significant changes in the hand washing habits and childhood diarrhoea incidence. ${ }^{20}$ The incidence of diarrhoea was lowered by $53 \%(95 \% \mathrm{Cl},-65 \%$ to $-41 \%)$ in the intervention areas. ${ }^{20}$ The duration of illness was also reduced by $39 \%$ (counted in days). Moreover, the intervention had the major positive effects on those children who were suffering from moderate to severe malnutrition (statistics not provided in the evaluation study). ${ }^{20}$ The study showed the positive hopes in the social and behavioural intervention of the diarrhoeal control in children. Luby et al in their follow up in 2009 reported that sustainability of the project was limited. ${ }^{21}$ They found that despite increased awareness of appropriate techniques of hand washing in the intervention areas; the hand washing behaviour was declined and purchasing soap for the purpose did not increase significantly. They concluded that it was the limitation of the project which didn't focused on increasing willingness and motivation to purchase and use soap. ${ }^{21}$

\section{Intervention 3: School Led Total Sanitation, Nepal}

School Led Total Sanitation (SLTS) was initiated as a pilot program in Nepal in 2006 by Government of Nepal and UNICEF. ${ }^{5,13,14,22}$ The program aims at creating demand of sanitation services with focus on empowering people and change in hygienic behaviour. The quantitative target of this program is having $100 \%$ toilet coverage leading to open defecation free (ODF) school catchment area. ${ }^{13}$ The program focuses school as start point, student as change agent and school catchment area as targeted area.

The program is rural focused. The program utilizes matching fund and revolving fund so that poor communities can get loan to build toilets in their houses. By 2009, it was seen that this program had reached to 15 districts and 90,000 households through 300 schools. ${ }^{13,22}$ Of the 300 schools, 250 school catchment areas were declared as open defecation free areas. As a result, diarrhoea incidence and prevalence is reported to decrease but formal outcome evaluation is yet to be done to see the extent of effect on reduction of disease. ${ }^{13}$

UNICEF source further adds that SLTS program is community centred, innovation flexible, local partnership oriented, 
and focuses on local ownership. ${ }^{13,22}$ This is a participatory approach utilizing participatory rural appraisal tools like social mapping and coverage mapping in planning process at local level. By building a support to create an environmental change, it seeks to achieve permanent behaviour change. But, SLTS has some challenges as well. This program depends widely on the leadership of teachers as facilitators to mobilize child clubs; and there is high cost of training teachers and maintaining revolving fund and matching fund. Moreover, the impact of program on reduction of childhood diarrhoea is often less recorded and less measured. ${ }^{13,22}$

\section{Intervention 4: Global Public Private Partnership for Hand washing with Soap, Ghana}

Global Public Private Partnership for Hand Washing with Soap (GPPPHWS) program started in nine different countries including Ghana. ${ }^{23}$ Program was based on marketing approach of soap. Three largest soap manufacturer (Colgate-Palmolive, Uniliver and Procter and Gamble), the World Bank and UNICEF joined together with national government to work on the common agenda of promoting hand washing with soap. Primary target groups were mothers having young children and secondary target group were school children. The program was formally started in September 2003 in Ghana. The program utilized three fold strategies; mass media campaign, district and community level activities and direct consumer contact. During whole program, the habit of hand washing was presented as socially desirable activity, and emotional disgust was linked with the behaviour by using various video clips showing germs in the hands after using toilet and cleaning child's bottom. ${ }^{23}$

The baseline study done in 2002 Ghana showed that only 4 $\%$ mothers used to wash their hands with soap after using toilet, and only $2 \%$ mothers washed their hands with soap after cleaning child's bottom. ${ }^{17,23}$ Study conducted after one year of implementation showed that hand washing before eating reached $41 \%$, hand washing after using toilet reached $13 \%$, and hand washing after washing child's bottom reached $41 \%$. It was also found that $82 \%$ of the mothers recalled the campaign and $48 \%$ could tell the song of the campaign. ${ }^{17,24}$

It was noted that the partnership with marketing agencies helped the national public health authorities to utilize marketing strategies. ${ }^{17,23,25}$ The activities were based on the marketing researches and hence yielded effective results. Although these were the strengths of program, there were some challenges within the program. The program was disrupted in India as it was interpreted as the propaganda of multinational company and the World Bank to displace local soap companies. In Ghana, the resources of public health authorities were also mobilized by companies and marketing agencies which may be politically unacceptable in many countries. As this program utilised a number of partners of completely different background, motive and ways of working, building partnership is not an easy task. The partnership is slow; results are even slower which may be a disincentive for political leadership who always seek immediate output. ${ }^{24-26}$

\section{DISCUSSION}

The findings of the successful program analysed in our study have different feasibility for implementation in Nepal. Though studies say that Saniya project is replicable, it should be noted that only health message is not sufficient in the places like Nepal where water supply is often inadequate and not even safe; and a large share of population is under poverty line which directly deter building toilets at their houses leading to open defecation. Problem in Nepal is even worsened as no law is clearly enforced to build toilet as mandatory requirment especially in rural areas. ${ }^{11,16,27}$ For these reasons, the program may have limited outcomes in Nepal.

Sanitation program implemented in Pakistan was not sustainable. Providing all commodities for hand washing free of cost is not feasible in Nepal. Moreover, such supplies will not yield long lasting efforts. Hence, the program is also not replicable in Nepal.

To adopt the School Led Total Sanitation (SLTS) approach in other districts of Nepal, some points should be considered. There is need of special subsidy for the people who are very poor and cannot build toilets in their houses. But in the meantime, proper utilization of such subsidies needs to be ensured. More importantly, it is also necessary to provide onsite technical help to the households who are willing to build toilet. This program may also consider multiple sources of message on adopting sanitation measure. To optimize the resources, this can be done by linking with existing health education activities of Ministry of Health of Nepal. Before implementing the program, proper baseline should be established and progress should be assessed during implementation. As The program involved the large amount of investment, district sanitation multi-year work plan and joint resource mobilisation is crucial to meet such resource requirement. ${ }^{13,14}$

Replication of GPPPHW program in amended form may be another feasible intervention in Nepal. National public health authorities can ask for marketing expertise from soap industries to reach the audience rather than just asking for donations. To tackle the risk of political propaganda as happened in India, the partnership of local companies must be ensured. ${ }^{23}$ This kind of partnership is complicated. A basket fund, joint technical and marketing committee to facilitate the activities and a joint monitoring body may be a good option to foster better partnership. ${ }^{23}$

\section{Possible non medical interventions in Nepal}

From the reviews of different approaches as presented above, a combination of SLTS and GPPPHW may be a better approach to implement in Nepal in larger scale. The 
combination of these approaches ensures demand creation for sanitation, gives momentum to ODF movement and simultaneously will help community with skills and increase the practice of hand washing with soap. ${ }^{14,17}$ Although randomized controlled trials on these two evaluations are not done, there are proven evidences from observational studies in reduction of diearrhoeal diseases. ${ }^{17}$

SLTS as having foundation on school can have a large number of change agents all over Nepal. ${ }^{13}$ This program by modifying key hygienic behaviour including hand washing and proper stool management can ultimately reduce episodes and mortality of childhood diarrhoea. ${ }^{13}$ As district development councils have started using district basket fund for sanitation, there is feasibility of obtaining resources from local resources (as outlined in government grant guidelines), national government (incentives for ODF district) and a number of international agencies. ${ }^{24,28}$ Apart from the technical issues, strong network of schools up to grassroots level; parent teacher associations; and school management committees are some of the important assets of this program. The other major advatnage with this approach is that students are easier target group to put forward new knowledge and skills; and change towards socially desirable behaviours. The change is likely to be sustainable if it is brought through students' involvement.

Importantly, there is need to create a pro poor safety net for ultra poor household for supporting toilet construction. ${ }^{14}$ There is also need to consider onsite/ ondemand technical support for constructing long lasting and user friendly toilets (suitable for children, adults, girls/ woman and people with physical disabilities). ${ }^{14}$ While considering pro poor safety nets, the original idea of SLTS "empowering community to support themselves" should not be overshadowed by susidies. SLTS relies on the fact that community has the capacity to manage basic facilities of sanitation. The main theme behind this philosophy is that the previously adopted donation model of sanitation measures had questions over sustainability, trickle down effects upto ultra poor level and the practice of donationorientated development even for the facilities that could be managed by the local resources. Alternative models for this approach could be providing work for the ultrapoor families of the communities and the local bodies can provide sanitation facilities in exchange. This may lead to slower progress but into greater sustainability pathway. The program largely depends on the leadership of school teachers who are already burdened with loads of their own primary role as teacher. Sanitation issue is not the only priority of the school management. The school management committees are busy with their regular responsibilites of managing school facilites and academic environment. This might be a challenge to get proper attention of the committee to sanitation issue. Current focus of the SLTS is also incorporating gender friendly sanitation facilities for female students which do mean that there may be need of modification of physical environment in those schools which already are supposed to have good sanitation facilities. Another major challenge associated with SLTS is cost of the program. As this program adopts multiple activities and multiple stakeholders which means demand of larger investment for sanitation facilities. Investment in sanitation,although already proved to be having returns of as high as seven times needs to persuade local government, political parties, funding agencies which may be a daunting task. ${ }^{19}$ However, if baseline and progress of the activities were reported in terms of benefits of reduction of morbidity, and mortality related to childhood diarrhoea, indirect economic and social benefits, convincing and obtaining commitment of stakeholders would be easier than it seems to be.

Public private partnership for hand washing with soap should be a complementary program rather than a standalone program. As this program targets mothers of children and aims at changing hand washing behaviour after using toilet, cleaning child's bottom and before feeding the child and there is strong evidence of good impact (up to $47 \%$ ) in reducing childhood diarrhoea, it can be concluded that this approach could invariably be useful in reducing childhood diarrhoe. ${ }^{17,19}$ This approach could buy-in the expertise of marketing agencies. Moreover, this program is also in line with public private partnership policy of Nepal. ${ }^{4}$ Given that several soap manufacturers are already implementing such hand washing with soap campaigns like; Clean hand-Good Health by Colgate, reach one billion people by 2012 by Lifebuoy,there is strong possibility of partnership for hand washing with soap..22 There should be ongoing research so that strong evidence could be presented to reduce childhood diarrhoeal disease.

There are some strengths and limitations of our study. We put forwarded a pragmatic view on feasible social and environmental intervention to reduce diarrhoea in Nepal. To best of our knowledge, previous studies did not summarize and suggest these models. Likewise, our study also supports the existing evidence that community empowerment is essential for sustainable change in the society. Our study is not free from limitations. We did not conduct a systematic review on individual behaviour changes (hand washing, toilet construction) as they were already conducted by other authors. ${ }^{18,19,25}$ We limited our study to the interventions in the developing countries. While the interventions from the developing countries are comparable to Nepal, it cannot be denied that successful interventions in developed countries cannot be overlooked.

\section{CONCLUSION}

Childhood diarrhoeal disease is a major killer disease among under five children in Nepal having death toll of around $13000 .{ }^{4}$ As available intervention is sufficient to avert CDD morbidity and mortality, current morbidity and mortality is not justifiable. Although four interventions discussed in this paper were successful, this review recommends 
combination of School Led Total Sanitation and Global Public Private Partnership for Hand washing with Soap to scale up in Nepal. The combination of both approaches

\section{REFERENCES}

1. Nepal. Ministry of Health \& Population. Population Division. New ERA (Firm : Kathmandu Nepal), Macro International. Nepal demographic and health survey, 2011. Kathmandu: Population Division, Ministry of Health and Population, Govt. of Nepal; 2011.

2. Department of Health Services. Annual Report. In: Ministry of Health and Population, editor. Kathmandu: Department of Health Services; 2009/10.

3. Bryce J, Daelmans B, Dwivedi A, Fauveau V, Lawn JE, Mason E, et al. Countdown to 2015 for maternal, newborn, and child survival: the 2008 report on tracking coverage of interventions. Lancet. $2008 \mathrm{Apr}$ 12;371(9620):1247-58.

4. Department of Health Services. Annual Report. In: Ministry of Health and Population, editor. Kathmandu: Department of Health Services; 2008/2009.

5. UNICEF. Evidence base: Water, Sanitation and Hygiene Interventions. New York: UNICEF 2009.

6. Aiello $A E$, Larson $E L$. What is the evidence for a causal link between hygiene and infections? Lancet Infect Dis. 2002 Feb;2(2):103-10.

7. Feachem RG, Koblinsky MA. Interventions for the control of diarrhoeal diseases among young children: measles immunization. Bulletin of the World Health Organization. 1983;61(4):641-52.

8. T. V. Nguyen, P. L. Van, C. L. Huy, K. N. Gia, A. Weintraub. Etiology and epidemiology of diarrhea in children in Hanoi, Vietnam. International Journal of Infectious Diseases JID. 2006;10(4):298-308.

9. W. A. Hanekom, G. D. Hussey. Vitamin A and Immunity Against Infections. Clinical Immunology Newsletter. 1996;19(7/8):102-3.

10. World Health Organization, United Nations Children's Fund. Diarrhoea: Why children are still dying and what can be done 2009.

11. United Nations Children's Fund. Nepal Statistics. 2011 [April 4, 2011]. Available from: http://www.unicef.org/infobycountry/nepal_nepal_ statistics.html.

12. Ghimire M, Pradhan YV, Maskey MK. Community-based interventions for diarrhoeal diseases and acute respiratory infections in Nepal. Bulletin of the World Health Organization. 2010 Mar;88(3):216-21.

13. United Nations Children's Fund. School children lead sanitation drive in Nepal. 2011 [April 5, 2011]. Available from: http://www.unicef. org/wash/nepal_39817.html.

14. Bell B. Analysis of School Led Total Sanitation in Chitwan, Nepal [Master's Thesis]. Utrecht [The Netherlands]: Utrecht Universit y 2010.

15. Curtis V, Kanki B, Cousens S, Diallo I, Kpozehouen A, Sangare M, et al. Evidence of behaviour change following a hygiene promotion programme in Burkina Faso. Bulletin of the World Health Organization. 2001;79(6):518-27.

16. Borghi J, Guinness L, Ouedraogo J, Curtis V. Is hygiene promotion cost-effective? A case study in Burkina Faso. Trop Med Int Health. 2002;7(11):960-9. will help in improving sanitation status, creating demand of sanitation and improving hand washing which are proven to be effective in reducing diarrhoeal diseases. ${ }^{8,29}$

17. Bell B. Analysis of School Led Total Sanitation in Chitwan, Nepal. MSc in Sustainable Development The Netherlands: Utrecht Universit y Utrecht; 2010.

18. Norman G, Pedley S, Takkouche B. Effects of sewerage on diarrhoea and enteric infections: a systematic review and meta-analysis. Lancet Infect Dis. 2010 Aug;10(8):536-44.

19. Curtis V, Cairncross S. Effect of washing hands with soap on diarrhoea risk in the community: a systematic review. Lancet Infect Dis. 2003 May;3(5):275-81.

20. Luby SP, Agboatwalla M, Painter J, Altaf A, Billhimer WL, Hoekstra RM. Effect of intensive handwashing promotion on childhood diarrhea in high-risk communities in Pakistan: a randomized controlled trial. JAMA the journal of the American Medical Association. 2004 Jun 2;291(21):2547-54.

21. Luby SP, Agboatwalla M, Bowen A, Kenah E, Sharker Y, Hoekstra RM. Difficulties in maintaining improved handwashing behavior, Karachi, Pakistan. Am J Trop Med Hyg. 2009 Jul;81(1):140-5.

22. Curtis V, Schmidt W, Luby S, Florez R, Touré O, Biran, A. Hygiene: new hopes, new horizons. The Lancet infectious diseases. 2011; 11(4): 312-321.

23. Curtis VA, Garbrah-Aidoo N, Scott B. Ethics in public health research: masters of marketing: bringing private sector skills to public health partnerships. American journal of public health. 2007 Apr;97(4):63441.

24. Collins C, Omar M, Adhikari D, Dhakal R, Emmel N, Dhakal MR, et al. Health system decentralisation in Nepal: identifying the issues. $J$ Health Organ Manag. 2007;21(6):535-45.

25. Peal A, Evans B, Voorden CVD. Hygiene and Sanitation Software An Overview of Approaches. Geneva: Water Supply \& Sanitation Collaborative Council 2010.

26. The World Bank. Public-Private Partnership for Handwashing (PPPHW). 2011 [cited 2011 May 16]. Available from: http://water. worldbank.org/water/shw-resource-guide/promotion/hygienepromotion-approaches/ppphw[16/05/2011.

27. N.R Warner, J Levy, K Harpp. Drinking water qualtiy in Nepal's Kathmandu Valley: a survey and asssessment of selective controlling sites characteristics. Hydrogeology Journal. 2008;16:321-34.

28. Jha C, Prasai S, Hobley M, L. B. Citizen Mobilisation in Nepal: Building on Nepal's Tradition of Social Mobilisation to make Local Governance more Inclusive and Accountable. Kathmandu [Nepal]: World Bank, Department for International Development (DFID) and Swiss Development Cooperation (SDC)2009.

29. Pretus D, Jones O, Sharma L, Shrestha R. Money down the pan? Community-level models for financing sanitation in rural Nepal: a sector review. Mandaluyong City, Phil: Asian Development Bank 2008. 